\title{
MELHORIA DA QUALIDADE E PRODUTIVIDADE DA CONSTRUÇÃO CIVIL DE CRATEÚS, CE: INSERINDO A UNIVERSIDADE NA COMUNIDADE COM AÇÕES EXTENSIONISTAS
}

Francisco Alverne Albuquerque Paiva Junior - alvernepaiva.ufc@gmail.com

Thaynara Soares de Oliveira - thaynara@alu.ufc.br

Luis Luis Felipe Cândido - luisfcandido2015@gmail.com

Núcleo de Inovação na Construção, Universidade Federal do Ceará, Campus de Crateús BR 226, Km 4, Venâncios

63.700-000 - Crateús - Ceará

Resumo: A Construção Civil é um importante setor econômico responsável pela transformação do ambiente natural em construído. Apesar de sua importância, o setor é marcado por diversos problemas como a baixa qualidade e baixa produtividade, tendo a baixa qualificação da mão de obra uma das suas causas principais. Essa característica está presente em obras de todos os portes e, principalmente, em pequenas construções, executadas em sua grande maioria de modo informal e sem o acompanhamento profissional adequado. Esse é o caso das obras na cidade de Crateús e que levou a realização da ação reportada nesse artigo que consistiu na capacitação técnico-profissional de operários da construção civil de Crateús. A partir de estudo prévio, que identificou demandas formativas para o setor, desenvolveu-se treinamentos sobre Saúde e Segurança no Trabalho (SST) para os operários. Para tal, realizou-se pesquisa bibliográfica de modo a desenvolver conteúdos compatíveis com o perfil dos participantes. Foi possível, também, constatar in loco a informalidade na execução dos serviços, o desconhecimento dos operários sobre SST e as condições adversas de trabalho. $O$ treinamento apresentou não só situações de risco, mas de doenças ocupacionais que podem se manifestar em longo prazo e que, muitas vezes, não são associadas ao trabalho. Para muitos operários, o treinamento realizado foi o primeiro contato que tiveram com o assunto, mesmo que eles já estivessem empregados no setor há anos. Por fim, o presente projeto possibilitou integrar as áreas de ensino, pesquisa $e$ extensão, inserindo a universidade na solução de problemas reais na comunidade de Crateús.

Palavras-chave: Extensão. Cooperação Universidade-Indústria. Saúde e Segurança do Trabalho.

\section{INTRODUÇÃO}

A Indústria da Construção Civil (ICC) no Brasil é uma das mais expressivas no mundo, compondo cerca de $2 \%$ da indústria global (KASSEM, DE AMORIM, 2015). Ela também é uma grande geradora de empregos e responsável pela absorção de uma significativa parcela da mão de obra não qualificada brasileira (MELLO; AMORIM, 2009), o que a torna fundamental para a economia.

Contudo, o setor é marcado por diversos problemas como a baixa qualidade dos produtos e a baixa produtividade dos serviços (MACIEL; CÂNDIDO; ROCHA, 2019), bem como a baixa especialização da mão de obra, que pode estar na raiz desses problemas (COSTA, 2011). Tal fato se encontra presente, em empresas de todos os portes, especialmente nas Micro e Pequenas Empresas (MPEs) (SOUSA; COSTA; CÂNDIDO, 2019). 
As MPEs são fundamentais para ICC e representam grande parcela de sua composição. Elas são um importante instrumento de inserção social, sendo responsáveis pela geração de uma grande quantidade de empregos (SOUZA et al., 2014). Contudo, dentre as principais características das empresas desse porte tem-se o baixo poder aquisitivo para investir em sistemas de gerenciamento e infraestrutura, e a má qualificação da mão de obra, além do baixo poder de negociação e alta mortalidade (COSTA; MENEGON, 2007).

As MPEs estão presentes tanto nas grandes, como nas pequenas cidades, sendo para estas últimas sua grande porção. Nesse contexto, em virtude da expansão das Universidades e Institutos Federais para o interior do Brasil vislumbra-se uma grande oportunidade de qualificar as empresas nos pequenos centros urbanos, bem como ajudar a diminuir a sua grande taxa de mortalidade.

Desta forma, a presente pesquisa explorou essa relação Empresa-Sociedade, ao analisar a experiência extensionista de capacitação profissional realizada por uma Universidade Federal do Ceará em seu campus avançado no interior do estado. Pode-se destacar a importância da inserção da universidade na comunidade, bem como a importância da extensão na formação de engenharia, pois, de acordo com Gonçalves (2015), a extensão é vista como uma forma de estender o conhecimento presente no ambiente acadêmico para a sociedade, sendo por diversos anos um importante vetor da disseminação dos benefícios acadêmicos para a população.

Contudo, por mais que o princípio da educação e a indissociabilidade entre Ensino, Pesquisa e Extensão esteja presente no artigo 207 da constituição brasileira de 1988 (GONÇALVES, 2015), é possível identificar no âmbito acadêmico que a extensão não é algo obrigatório nas estruturas curriculares universitárias, sendo as iniciativas difusas e dispersas. Esta situação tende a mudar, uma vez que foi regulamentada pela Resolução $\mathrm{n}^{\circ} 7$ MEC/CNE/CES, de 18 de dezembro de 2018, a curricularização da extensão, ou creditação (curricular) da extensão - estratégia prevista no Plano Nacional de Educação (PNE), e que ainda estão em fase de implementação nos currículos dos cursos de todo o Brasil.

Neste sentido, o trabalho se justifica ao contribuir com a apresentação de iniciativas de sucesso que possam ser replicadas para outras realidades no âmbito da curricularização da extensão, além da qualificação da mão de obra promovida no projeto aqui relatado.

\section{REFERENCIAL TEÓRICO}

Nesta seção, apresenta-se o referencial teórico concentrando-se nas características da construção civil em geral e das MPE, em particular, e sobre Saúde e Segurança do Trabalho.

\subsection{Micro e Pequenas Empresas na Construção Civil}

A expansão da demanda habitacional e necessidade da melhoria da qualidade do ambiente construído tem se mostrado desafiador diante das características do setor da construção civil, que ainda guarda traços artesanais de produção, resistência à modernização e atualização dos processos (GONSALEZ, 2017), baixa qualificação da mão de obra (ANDRADE; BIZZO, 2019) e dificuldades para o cumprimento de normas técnicas (MOREIRA; LIMA; CÂNDIDO, 2018).

Este cenário é mais complexo em pequenas cidades, devido à expectativa de baixa profissionalização do setor, uma vez que a maior concentração de profissionais técnicos sempre ocorreu nas grandes metrópoles, especificamente em construções de médio e grande porte (CRUZ; CARVALHO; SANTOS, 2017) e onde superabundam pequenas construções, que são executadas em sua grande maioria de modo informal, como é o caso do setor na cidade de Crateús, local onde o estudo foi desenvolvido. 
De acordo com Sousa, Costa e Cândido (2019), as empresas da ICC do município de Crateús são majoritariamente MPEs, e apresentam os problemas e desafios já destacados por outras pesquisas para empresas desse porte (COSTA; MENEGON, 2007; SOUZA et al., 2014). Contudo, os autores identificaram algumas dificuldades específicas da região que têm servido para subsidiar estudos por parte da população acadêmica recém ingressa na região.

Isto tem permitido o desenvolvimento de TCCs, projetos de extensão, entre outros, que têm possibilitado uma maior integração entre a população acadêmica e região crateuense, ratificando que a literatura que aponta para importância de instituições de ensino superior como fator para o desenvolvimento local é vasta e, segundo Brandli (2004) fomenta a valorização dos recursos próprios locais e atrai pessoas.

\subsection{Saúde e segurança do trabalho na construção civil}

A maior parte dos países possuem legislação de proteção dos trabalhadores, seja nos aspectos contratuais ou diretrizes para diminuir o risco de acidente no ambiente de trabalho (TORP; MOEN, 2006). No Brasil, tais regulamentações estão contidas nas Normas Regulamentadoras (NR), projetos e programas de segurança no trabalho, e Consolidação de Leis de Trabalho (CLT) (COSTA; MENEGON, 2008).

Contudo, Jensen (2001) aponta para a falta de adesão a normas e métodos que garantam as condições de Saúde e Segurança no Trabalho (SST) por parte de pequenas empresas. De acordo com o autor, um dos grandes motivos para isso é a falta de conhecimento que esse tipo de empresa possui, o que leva contratantes e contratados a crerem que atitudes em prol de melhorias de SST não sejam relevantes e investimentos nessa área não devam ser priorizados.

Em função disso, não é de se espantar que um cenário mais agravado para as condições de SST possa surgir em MPEs. De acordo com Freitas (2016), 61\% dos acidentes fatais devido a quedas ocorre em obras com 10 ou menos trabalhadores. Pesquisas apontam que um dos grandes motivos para esse grave cenário é a falta de conhecimento e treinamento que os trabalhadores da área possuem (JENSEN, 2001; FREITAS, 2016; COSTA, 2011).

Assim, diante desse quadro priorizou-se inicialmente na ação extensionista a questão de saúde e segurança, o que é reportado neste trabalho, que trouxe como a universidade se inseriu em treinamentos de trabalhadores das MPEs de construção na região de Crateús.

\section{MÉTODO DE PESQUISA}

Esse artigo buscou apresentar a experiência realizada na cidade de Crateús, CE no âmbito do Projeto de Extensão "Melhoria da qualidade e produtividade da Construção Civil de Crateús, CE" que promoveu qualificação de operários da construção civil local. Tal capacitação promoveu uma maior inserção no mercado de trabalho e um aumento da qualidade e da Saúde e Segurança do Trabalho na região, temática escolhida a partir da identificação prévia de demandas do setor local, como relatado por Sousa, Costa e Cândido, (2019). Permitiu, ainda, que a Universidade se inserisse na comunidade local cumprindo, desta forma, uma relevante função social para Crateús.

Crateús é uma cidade de pequeno porte que possui cerca de 72 mil habitantes (IBGE, 2010) e está localizada na região do oeste do estado do Ceará a cerca de $350 \mathrm{~km}$ da capital Fortaleza, divisa com o estado do Piauí. Marcada por um clima semiárido, população de baixa renda, e distante dos principais centros urbanos do estado do Ceará e do Piauí, Crateús tornouse um polo de desenvolvimento regional que hoje é conhecido como Sertão de Crateús, composto por 12 cidades.

O desenvolvimento da cidade foi alavancado com a instalação de diversas instituições públicas de educação como o campus avançado da Universidade Estadual do Ceará (UECE), 
do Instituto Federal de Educação, Ciência e Tecnologia do Ceará (IFCE) e da Universidade Federal do Ceará (UFC). De acordo com a Secretaria de Finanças da Prefeitura Municipal de Crateús no período de 2013 a 2019 houve um grande crescimento no número aprovações de alvará, ou seja, a cidade experimenta um crescimento com os diversos empreendimentos que estão surgindo por toda a cidade, seja de loteamentos ou de condomínios. Com esse "boom" imobiliário, faz-se pertinente que a Universidade possa atuar para a melhoria da qualidade de projetos e da produtividade das obras, de modo a proporcionar um bom desempenho para empresas e para as moradias e seus habitantes.

Desse modo, trabalho foi desenvolvido em três fases, conforme a Figura 1.

Figura 1 - Método de Pesquisa Adotado

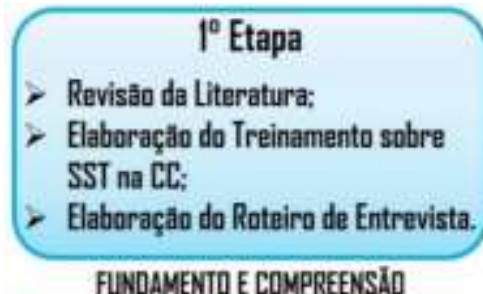

FUNDAMENTD E COMPREENSĨD

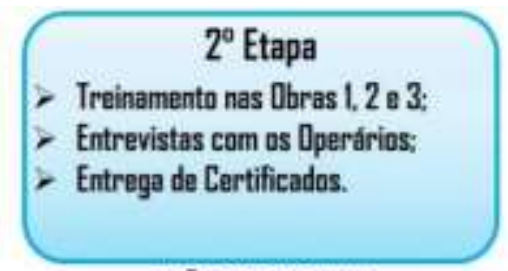

AČL̃ EXTENSIONISTA

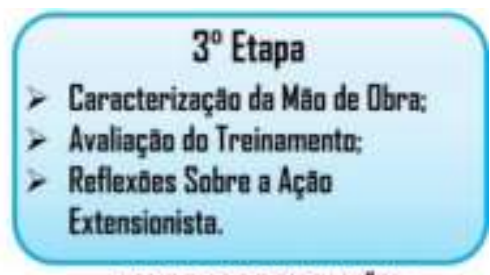

RESULTADOS E DISCUSSÖES

Fonte: dos autores.

A primeira etapa consistiu em uma revisão da literatura e um planejamento para que o treinamento desenvolvido fosse acessível a mão de obra enfocada pelo projeto. Após a primeira etapa, foi realizado o treinamento nas obras presentes na região de Crateús. $\mathrm{O}$ treinamento ocorreu em formato de aula presencial nas obras 1, 2 e 3, tendo-se coletado informações sobre os operários, por meio de um roteiro que cobria questões de identificação pessoal, situação social e profissional, bem como uma avaliação sobre o treinamento realizado. No fim, os operários receberam certificado de participação. A terceira etapa consistiu na caracterização da mão de obra e avaliação da qualidade do treinamento, o que permitiu analisar os resultados sobre o projeto desenvolvido.

\section{RESULTADOS E DISCUSSÕES}

Nesta seção apresentam-se os resultados que foram subdivididos em quatro partes: relato sobre o treinamento; caracterização dos operários participantes; avaliação do treinamento e; reflexão sobre a ação extensionista realizada.

\subsection{Saúde e segurança do trabalho na construção civil}

Os treinamentos realizados foram de SST nos canteiros de obra durante o mês de julho a novembro de 2019 em três empresas que operam na ICC em Crateús. Realizou-se uma aula presencial para os operários com entrega de certificado de conclusão para os participantes. A aula em questão foi ministrada por uma bolsista do projeto de extensão, e acompanhada pelo professor orientador do projeto.

A primeira obra consistia na ampliação de um laboratório de análises clínicas, anexo a um hospital local. A obra estava na fase de revestimentos argamassados e contava com 20 operários. Na ocasião, o proprietário da empresa também participou da aula, trazendo discussões de situações vividas pelos operários em obras passadas da empresa, conforme ilustrado na Figura 2. 
Figura 2 - Treinamento realizado na Obra 1 com a participação do gestor da empresa

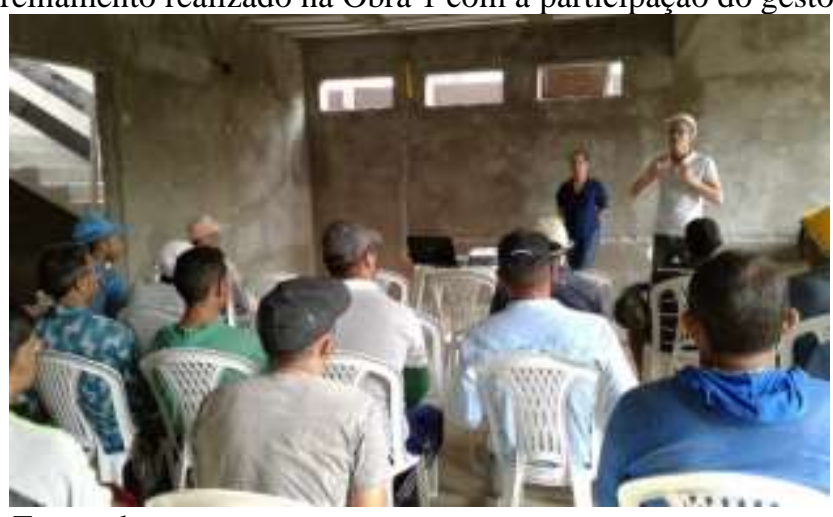

Fonte: dos autores.

A segunda obra consistia na construção do cinema da cidade e encontrava-se na fase de fundações. Observou-se instalações de canteiro de obras mais precárias, não dispondo, por exemplo, de assento para todos os operários no refeitório da obra, o que fez com que o treinamento tenha sido realizado em pé, como apresentado na Figura 3.

Figura 3 - Treinamento realizado na Obra 2

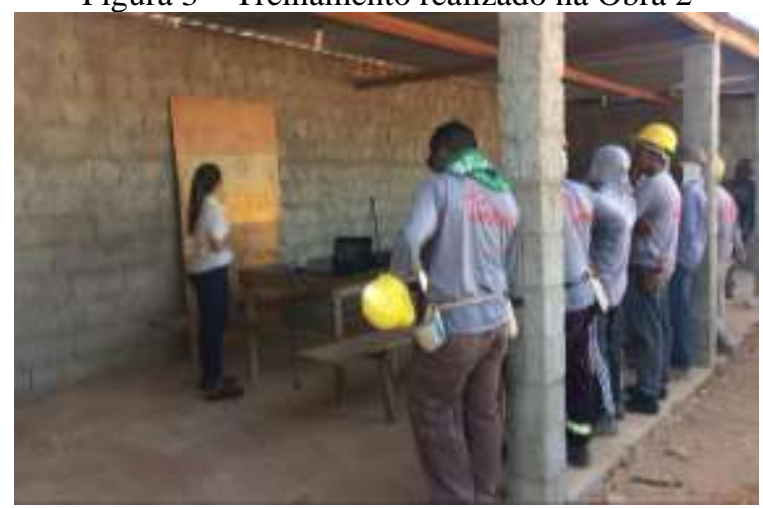

Fonte: dos autores.

A terceira obra consistia na construção de uma escola profissionalizante do Governo do Estado do Ceará. A obra estava na fase de acabamentos e, por ser uma obra pública, verificouse uma maior organização do canteiro, das instalações provisórias, bem como o uso de EPIs e EPCs. Apenas nessa obra foi relatada a realização de treinamentos prévios sobre segurança do trabalho. A Figura 4 apresenta a realização do treinamento realizado pelo projeto.

Figura 4 - Treinamento realizado na Obra 3

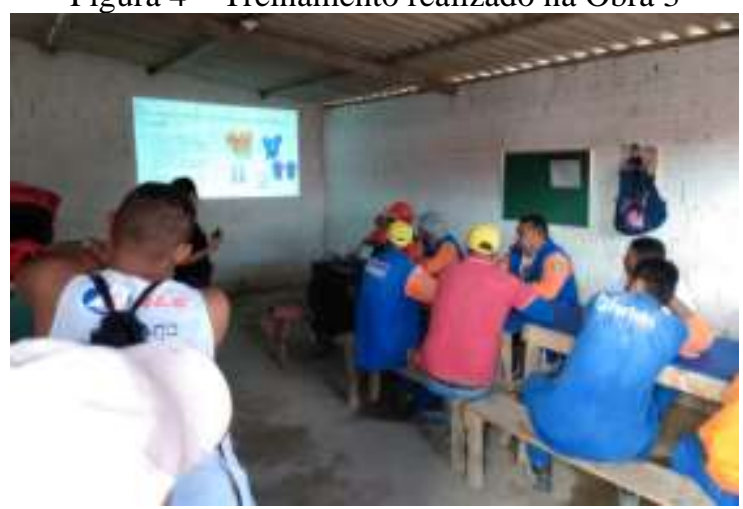

Fonte: dos autores. 
Foram abordadas questões relacionadas aos riscos no ambiente de trabalho da construção e as principais medidas de prevenção relacionadas aos equipamentos de proteção individual e coletivo (EPI e EPC), Organização do canteiro de obras e a Manutenção dos equipamentos.

Abordou-se, também, os tipos de acidente, incluindo o acidente de percurso e os direitos e deveres do empregador e empregados. Deu-se especial atenção as doenças decorrentes do trabalho inadequado, ou seja, as doenças ocupacionais, pois essas não se manifestam imediatamente e são negligenciadas pelos operários, tais como as perdas auditivas e a surdez provocadas pela exposição excessiva a que estão sujeitos, as doenças respiratórias e as lesões por esforço repetitivo.

No final, realizou-se uma dinâmica para averiguar a assimilação dos conhecimentos discutidos, apresentando-se vídeos com situações de risco (ou seguras) que os operários deveriam avaliar e explicar o que poderia estar inadequado, com o uso de plaquinhas sinalizando situação adequada (com um joinha para cima) ou inadequada (com um joinha para baixo), conforme exemplificado na Figura 4.

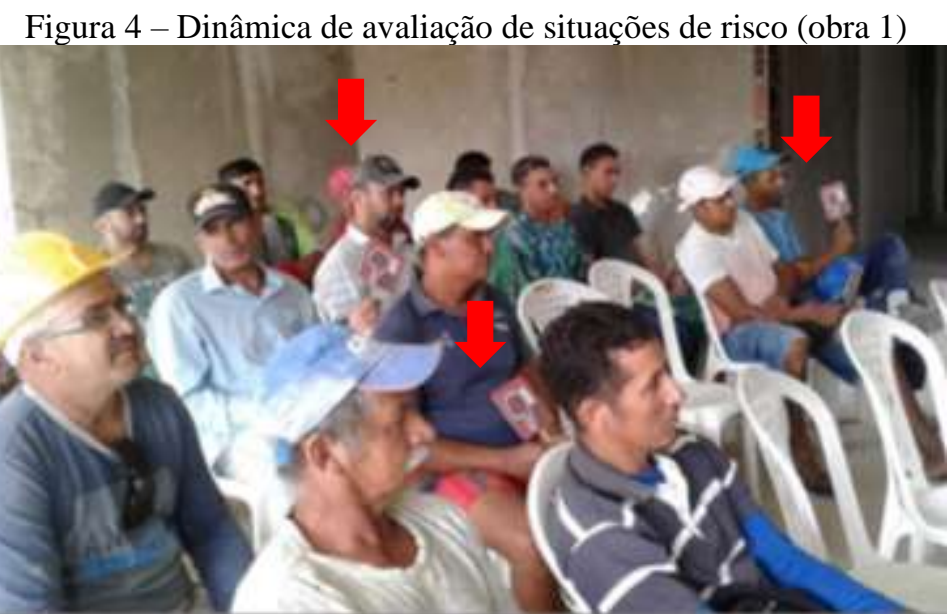

Fonte: dos autores.

Constatou-se, durante os treinamentos, a precária infraestrutura disponível para os operários em canteiro de obras, confirmando os aspectos de baixa profissionalização pertinentes as obras de pequeno porte (SOUZA; COSTA; CÂNDIDO, 2019). Itens básicos de primeiros socorros, extintores de incêndio e outras questões também não puderem ser identificadas. Os treinamentos, suscitaram com as empresas, a continuação dos trabalhos no futuro, como o planejamento do canteiro e de suas condições de segurança, bem como a verificação do cumprimento das condições de segurança no decorrer da obra.

\subsection{Caracterização dos operários}

Participaram ao todo 58 operários, dentre eles cerca de $65 \%$ estavam na faixa de 20 a 40 anos de idades, o que confirma resultados observados na literatura (NERI, 2011; CANTISIANI; CASTELO, 2015). Identificou-se, também, que 13\% de operários com idades acima de 60 anos, o que evidenciou a heterogeneidade de trabalhadores nos canteiros de obra.

Verificou-se que $87 \%$ dos trabalhadores possuem casa própria, acima dos $73 \%$ de condição de moradia própria do último censo do IBGE (2010). E mais, 91\% residem na própria cidade, corroborando que a cidade atraí trabalhadores de outras cidades da região.

Com relação à escolaridade, verificou-se que $70 \%$ dos trabalhadores tinham o fundamental incompleto, com $22 \%$ com nível médio incompleto, o que está alinhado com literatura. De acordo com Neri (2011), a média de anos estudados por trabalhadores da 
construção civil é de 2 anos a menos que a dos demais trabalhadores ativo no mercado. Além disso, em 2013, cerca de $70 \%$ de trabalhadores da construção civil apresentavam no máximo o ensino fundamental completo, com $60 \%$ sem ter completado ou ingressado no ensino fundamental (CANTISIANI; CASTELO, 2015).

$83 \%$ dos entrevistados informaram já ter recebido algum tipo de treinamento ao longo de sua atuação profissional, porém, quase que sua totalidade não soube informar quais. Com relação ao tempo de serviço, $43 \%$ estavam a no máximo 10 anos no setor, enquanto $30 \%$ estava entre 11 e 20 anos e o restante, 27\%, com mais de 20 anos de atuação. O que mais chamou a atenção, no entanto, foi que $61 \%$ destes trabalhadores tinham no máximo 10 anos de carteira assinada e $10 \%$ que sequer assinaram. Isso demonstra a grande informalidade de relações contratuais presentes em MPEs no Brasil (SOUZA et al.,2014).

\subsection{Avaliação do treinamento pelos operários}

O projeto de extensão foi muito bem recebido e avaliado pelos participantes, tendo no geral resultados bem positivos. Grande parte dos operários julgaram o conteúdo repassado útil para suas rotinas de trabalho. A consistência da informação também foi avaliada, em que cerca de $80 \%$ afirmaram que o conteúdo repassado foi claro ou muito claro. No tocante a satisfação geral, cerca de $95 \%$ afirmaram estar satisfeitos ou muito satisfeitos com a ação realizada. Não somente a satisfação foi elevada, como também todos os participantes recomendariam o curso e demonstram interesses por treinamentos futuros.

\subsection{Reflexões sobre a ação extensionista realizada}

A Universidade costumeiramente é vista como algo distante da realidade do local em que ela está instalada. Desta forma, para cumprir o seu papel social de maneira mais integral, as ações de extensão colocam discentes e docentes na oportunidade de vivenciar e propor soluções para problema sociais, se aproximando da sociedade e aumentando o seu preparo para o enfrentamento de problemáticas profissionais.

A ação extensionista proposta neste projeto possibilitou a integração das áreas do ensino, da pesquisa e da extensão, uma vez que promoveu o desenvolvimento das habilidades de docência e de pesquisa, por parte dos discentes envolvidos na pesquisa, elaboração e ministração dos treinamentos com o público alvo, bem como a constatação in loco das condições de trabalho dos operários da construção do setor de construção civil de Crateús. As atividades de capacitação técnico-profissional promovidas foram satisfatórias e de acordo com as demandas identificadas em estudo anteriores.

O desenvolvimento das atividades pode ainda fomentar materiais para as disciplinas do curso de Engenharia Civil do Campus, com a especificação da realidade local, e articulação de conceitos para as disciplinas de Higiene Industrial e Segurança do Trabalho, Projeto e Construção de Edifícios I e II, Gerenciamento da Construção Civil I e II, Engenharia Ambiental e Trabalho de Conclusão de Curso I e II, presentes no currículo do curso.

O trabalho realizado se mostrou como uma via de mão dupla, com o crescimento das partes envolvidas na extensão (sociedade e academia), o que corroborou com a literatura (GONÇALVES, 2015). Nesse sentido, o projeto de extensão "Melhoria da Qualidade e Produtividade na Construção Civil de Crateús, CE" teve sua continuidade aprovada pela universidade em 2020, avançando sobre outras temáticas previamente identificadas.

\section{CONSIDERAÇÕES FINAIS}

O presente artigo apresentou a experiência extensionista "Melhoria da qualidade e produtividade da Construção Civil de Crateús, CE" que consistia na qualificação da mão de 
obra da construção. Com a caracterização dos operários foi possível corroborar a literatura no sentido da baixa qualificação da mão de obra, com baixo nível de escolaridade e manifestação de desejo por qualificações. Foi possível, ainda, identificar um baixo nível de atendimento as exigências mínimas de SST in loco presentes na NR-18 e outras regulamentações pertinentes.

A ação extensionista trouxe um grande desafio para a elaboração do treinamento, de modo que fosse condizente com o público alvo. Uma análise sobre a linguagem adequada a se utilizar, o nível do conteúdo repassado, o tempo de duração dos cursos, a abordagem metodológica e o local de aplicação dos treinamentos foram estudados, de modo que fosse atingido melhores resultados. Isso trouxe um impacto positivo para os operários participantes, bem como para os membros da ação extensionista, alinhando-se com a visão de Leite (2016) sobre ações extensionistas serem importantes para a formação e profissionalização dos alunos de graduação, sendo vetor de disseminação de benefícios acadêmicos e profissionais.

Neste sentido, o trabalho contribuiu com a apresentação de uma iniciativa de sucesso que pode ser replicada para outras realidades no âmbito da curricularização da extensão, expandindo a literatura empírica sobre o tema. Possibilidades de continuação desse trabalho são viáveis, haja vista que a recepção dos participantes foi boa e o interesse em treinamentos futuros foi algo de interesse coletiva. Desta forma, o trabalho está sendo continuado com as temáticas de leitura e interpretação de projetos e manejo de RCD para os operários e ABNT NBR 15575: 2013 - desempenho de edificações habitacionais para gestores do setor de construção, objetivando melhorias da qualidade e desempenho do ambiente construído.

\section{Agradecimentos}

À Pró-reitoria de Extensão (PREX) da Universidade Federal do Ceará (UFC) pelo apoio recebido, as empresas que abriram suas obras e aos operários pelo tempo concedido.

\section{REFERÊNCIAS}

ANDRADE, Valdelis Fernandes de; BIZZO, Waldir Antonio. Corporate social responsibility in Brazil according to SA 8000: Case studies and the correlation with the supply chain. Journal of Cleaner Production, v. 210, p. 1022-1032, 2019.

BRANDLI, L. L. Modelo de demanda habitacional de estudantes numa perspectiva de desenvolvimento local. 2004. 308 f. Tese (Doutorado) - Curso de Engenharia de Produção, Programa de Pós-graduação em Engenharia de Produção, Universidade Federal de Santa Catarina, Florianópolis, 2004.

BRASIL. Resolução no 7 MEC/CNE/CES, de 18 de dezembro de 2018. Estabelece as Diretrizes para a Extensão na Educação Superior Brasileira e regimenta o disposto na Meta 12.7 da Lei no 13.005/2014, que aprova o Plano Nacional de Educação - PNE 2014-2024 e dá outras providências. Disponível em: < http://www.in.gov.br/materia//asset_publisher/Kujrw0TZC2Mb/content/id/55877808 > Acessado em: 28 jul. 2020.

CANTISIANI, A. F.; CASTElO, A. M. O perfil dos trabalhadores da Construção Civil. Revista Conjuntura da construção. Março. Rio de janeiro: FGV, 2015

COSTA, L. R. Subcontratação e informalidade na construção civil, no Brasil e na França. Caderno CRH, Salvador, v. 24, n. 62, p. 413-434, mai./ago. 2011. 
COSTA, D. C.; MENEGON, N. L. Condução de ações em Saúde e Segurança do Trabalho em pequenas e médias empresas: análise de três casos. Revista Brasileira de Saúde Ocupacional, v. 32, n. 116, p. 60-71, 2007.

COSTA, D. C.; MENEGON, N. L. Condução de ações em saúde e segurança do trabalho em pequenas e médias empresas: análise de três casos. Revista Brasileira de Saúde Ocupacional, v. 33, n. 117, p. 60-71, 2008.

CRUZ, H. M.; CARVALHO, W. S.; SANTOS, D. de G. Identificação de boas prátricas em pequenas obras. In: SIBRAGEC, Fortaleza. Anais... Fortaleza: SBTIC, 2017.

FREITAS, L. C. Manual de segurança e saúde do trabalho. Sílabo, 2016

GONÇALVES, N. G. Indissociabilidade entre Ensino, Pesquisa e Extensão: um princípio necessário. Perspectiva, v. 33, n. 3, p. 1229-1256, 2015.

INSTITUTO BRASILEIRO DE GEOGRAFIA E ESTATÍSTICA. Tabela (XLS)Mesorregiões, microrregiões e municípios do Ceará: Tabela 4.10.2.4 -Domicílios particulares permanente e moradores em domicílios particulares permanentes, por adequação da moradia, segundo as Mesorregiões, Microrregiões e os Municípios - Ceará - 2010. Disponível em: 〈encurtador.com.br/empF7>. Acesso em: 25 ago. 2019.

JENSEN, P. L; ALSTRUP, L; THOFT, E. Workplace assessment: a tool for occupational health and safety management in small firms?. Applied Ergonomics, v. 32, n. 5, p. 433-440, 2001.

LEITE P.H.N. et al. Programas de educação pelo trabalho e tutorial: diferentes enfoques dos grupos 'PET' no Brasil. Medicina, Ribeirão Preto. 2016; n.49. p.381-387. Disponível em: <encurtador.com.br/gsL48>. Acesso em: 12 de julho de 2020.

KASSEM, M.; DE AMORIM, S. R. L. BIM Building Information Modeling no Brasil e na União Europeia. 2015.

MACIEL, F. W. F; CÂNDIDO, L. F; ROCHA, V. F. T. PBQP-H e Norma de Desempenho: um estudo de múltiplos casos com micro e pequenas construtoras cearenses. In: SIBRAGEC, 11., 2019, Londrina. Anais [...]. Porto Alegre: ANTAC, 2019

MELLO, L. C. B. D. B.; AMORIM, S. R. L. de. O substor de edificações da construção civil no Brasil: uma análise comparativa em relação à União Europeia e aos Estados Unidos. Produção, v. 19, n. 2, p. 388-399, 2009.

MOREIRA, F.; LIMA, R. F.; CÂNDIDO, L. F. Os desafios para a implementação dos requisitos de desempenho acústico de acordo com a ABNT NBR 15.575/2013: um estudo de caso com construtoras cearenses. In: ENTAC, 18., 2018, Foz do Iguaçu. Anais... Porto Alegre: ANTAC, 2018. p. 2853-2860.

NERI, M. Trabalho educação e juventude na construção civil. São Paulo: Instituto, 2011, p.153. disponível:< https://sinapse.gife.org.br/download/trabalho-educacao-e-juventude-naconstrucao-civil > acesso em 28 jul. de 2020. 
TORP, S; MOEN, B. E. The effects of occupational health and safety management on work environment and health: A prospective study. Applied ergonomics, v. 37, n. 6, p. 775-783, 2006.

SOUSA, G. C. M.; COSTA, G. R.; CÂNDIDO, L. F. Critérios de sucesso na percepção de gestores de MPE de construção do semi árido nordestino. In: SIBRAGEC, 11., 2019, Londrina. Anais [...]. Porto Alegre: ANTAC, 2019

SOUZA, M. C. de A. F. de; et al. Pequenas empresas industriais de longa permanência no mercado: uma análise a partir da literatura e de evidências empíricas. Gestão \& Produção, v.21, n.1, p. 157-170, 2014.

\title{
IMPROVEMENT OF THE QUALITY AND PRODUCTIVITY OF THE CONSTRUCTION SECTOR IN THE CITY OF CRATEÚS, STATE OF CEARÁ, BRAZIL: INSERTING THE UNIVERSITY IN THE COMMUNITY WITH EXTENSIONIST ACTIONS
}

\begin{abstract}
The Civil Construction is an important economic sector responsible for natural environment transformation into built. Despite its importance, the sector is still marked by many problems such as low quality and low productivity, with the low quality of the workforce being one the main reasons. This characteristic is present in many constructions of all sizes, especially, in small ones executed mostly in informal manner without the accompanying of a suitable qualified professional. This is the case of constructions in the city of Crateus, that led to the realization of the action reported in this article, that consisted of the technical-professional training of construction workers. Starting from a previous study, that identified formative demands for the sector, trainings were developed about Occupational Health and Safety $(\mathrm{OH} \& S)$ for the workers. For that, a bibliographic research was carried in order to develop compatible contents for the participants profile. It was also possible to observe the on-site informality on service executions, the lack of knowledge of the workers about $O H \& S$ and the adverse working conditions. The training presented not only situations of rick, but occupational diseases that can manifest in long term and that, in many cases, are not associated with the work. The training was the first time that many of the workers had contact with the theme, even though they have been working in the sector for many years. Finally, this project enabled the integration of teaching, research and extension, inserting the university in the resolution of real problems in the community Crateús.
\end{abstract}

Keywords: Extension. University-Industry Cooperation. Health and safety. 